\title{
COMPARITIVE STUDY BETWEEN ICH GUIDELINE AND ANVISA GUIDELINE
}

\author{
Kritika Rai, Poornima Potphode, Chandan Gupta and Nutan Rao* \\ Oriental College of Pharmacy, Sanpada, Navi Mumbai, \\ Mumbai University, Maharashtra, India.
}

\begin{abstract}
In November 2016, The Brazilian National Agency for Health Surveillance (AgênciaNacional de VigilânciaSanitária - ANVISA) became a member of the International Council for Harmonisation of Technical Requirements for Pharmaceuticals for Human Use (ICH). Brazil was the first country in Latin America to join the ICH as a member, and together with South Korea, were the first two countries to be accepted into ICH as regulatory members. Joining the ICH, the agency has to fulfil with some obligations such as implementation of guidelines. As a commitment, within five years, ANVISA should adopt a set of five ICH guidelines that mainly concerns the Quality, Pharmacovigilance, Clinical Research, implementation of the Common Technical Document (CTD) and Medical Dictionary for Regulatory Activities (MedDRA). In which we have focused on Quality. The paper provides a critical assessment to implement the ICH guidelines in Brazil, with focus on the ICH guidelines for stability studies, analytical validation and pharmaceutical development. Both guidelines have been selected due to major differences between the current Brazilian regulations and ICH guidelines, leading to a huge challenge for the Brazilian Health Authority and the locally established Pharmaceutical Companies to implement these guidelines. Although many differences still in existing and efforts will be needed to implement the ICH guidelines in Brazil, ANVISA is putting a lot of efforts to implement the guidelines within the next years, in an open communication with the Industries, in order to reduce as much as possible, the impact. The implementation of the ICH guidelines will bring many benefits for the Industry and Regulator. By implementing the ICH guidelines in Brazil, the country will contribute to the global regulatory harmonisation, which will bring a great benefit to the public health and important medicines will be faster available to the patients.
\end{abstract}

Keywords: ICH guidelines, ANIVISA guidelines, WHO, Stability Studies.

\section{HISTORY}

ICH

In the 1980s the European Union began harmonizing regulatory requirements. In 1989, Europe, Japan, and the United States started creating plans for harmonisation. The International Conference on Harmonisation of Technical Requirements for Registration of Pharmaceuticals for Human Use (ICH) was designed in April 1990 at a meeting in Brussels. The initial goal of $\mathrm{ICH}$ is coordinating the regulatory activities of the European, Japanese and United States regulatory bodies in consultation with the pharmaceutical trade associations from these regions, to discuss and agree the scientific aspects arising from product registration. ${ }^{1}$ Since the new millennium, ICH's 
observation has been directed towards extending the benefits of harmonisation beyond the founding $\mathrm{ICH}$ regions. In 2015, $\mathrm{ICH}$ was named as International Council for Harmonisation of Technical Requirements for Pharmaceuticals for Human Use while becoming anofficial association in Switzerland as a non-profit organisation. ${ }^{2,3}$ The objective of these reforms was to transform $\mathrm{ICH}$ into a truly global initiative supported by a powerful and transparent governance structure. ${ }^{4}$ The $\mathrm{ICH}$ Association established an Assembly as the broadscalegoverning body with an objective of focusing global pharmaceutical regulatory harmonisation work in one venue that permits pharmaceutical regulatory authorities and concerned industry organisations to be more passionately involved in ICH's harmonisation work. The new Assembly met for the first time on 23 October $2015 .{ }^{5}$

\section{ANVISA}

Brazilian Health Regulatory Agency (in Portuguese, AgênciaNacional de VigilânciaSanitária) is a regulatory body of the Brazilian government, build in 1999 during President Fernando Henrique Cardoso's term of office. It is authoritative for the regulation and approval of pharmaceutical drugs, sanitary standards and regulation of the food industry.

The agency bills itself as "an independently administered, financially autonomous" regulatory body. It is administered by a fivemember collegiate board of directors, who oversee five thematic directorates, assisted by a five-tier oversight structure. ${ }^{5}$ Since September 2018 the agency is headed by William Dib. ${ }^{6}$

\section{INTRODUCTION}

International Council for Harmonization of Technical Requirements for Pharmaceuticals for Human Use (ICH)

The International Council for Harmonization of Technical Requirements for Pharmaceuticals for Human Use $(\mathrm{ICH})$ is an initiative that brings together regulatory authorities and pharmaceutical industry to discuss scientific and technical aspects of pharmaceutical product development and registration.

The ICH mission is to promote public health by achieving greater harmonization through the growth of technical Guidelines and requirements for pharmaceutical product registration. ${ }^{\top}$

Harmonization ends up in a lot of rational use of human, animal and different resources, the elimination ofunnecessary delay within the international development and handiness of latest medicines whereas maintaining safeguards on quality, safety, efficacy, and regulatory obligations to protect public health.

As per the public health $\mathrm{ICH}$ must include the professional qualifications in their requirements on the expect of pharmacists must be qualified and organizations should be enclosed solely pharmacist connect ed of all health organization.

The ICH comprises the following bodies: ${ }^{8}$

1. ICH Assembly

2. ICH Management Committee

3. MedDRA Management Committee

4. ICH Secretariat

The ICH Assembly brings alongall Members and Observers of the $\mathrm{ICH}$ Association as the overarching governing body of $\mathrm{ICH}$. It adopts decisions in particular on matters such as on the adoption of $\mathrm{ICH}$ Guidelines, admission of recent Members and Observers, and the $\mathrm{ICH}$ Association's work plans and budget. Member representatives appointed to the Assembly are supported by $\mathrm{ICH}$ Coordinators who represents Member to the $\mathrm{ICH}$ Secretariat on a usual.

The ICH Management Committee (MC) is the body that oversees operational aspects of $\mathrm{ICH}$ on behalf of all Members, as well as administrative and financial matters and oversight of the Working Groups (WGs).

The MedDRA Management Committee (MC) is responsible for direction of MedDRA, ICH's standardized medical terminology. The MedDRA MC has the role of managing, supporting, and facilitating the maintenance, development, and dissemination of MedDRA. ${ }^{9}$ The ICH Secretariat is responsible for day-today management of $\mathrm{ICH}$, coordinating $\mathrm{ICH}$ activities as well as providing support to the Assembly, the MC and Working Groups and also provides support for the MedDRA MC. The $\mathrm{ICH}$ Secretariat is located in Geneva, Switzerland.

When a new technical topic is accepted for harmonization the $\mathrm{ICH}$ WGs are established by the Assembly, and are charged with developing a harmonized guideline that meets the objectives outlined in the Concept Paper and Business Plan. Face-to-face conference of the WG will normally only take place during the biannual ICH meetings. Interim reports are created at every meeting of the Assembly and made publicly available on the $\mathrm{ICH}$ website.

Guidelines

The ICH topics are divided into four categories and $\mathrm{ICH}$ topic codes are assigned according to these categories ${ }^{10}$

Q : Quality Guidelines

$S$ : Safety Guidelines

E : Efficacy Guidelines 
$M$ : Multidisciplinary Guidelines

$\mathrm{ICH}$ Guidelines don't seem to be necessaryfor anybody per se but the strength of the $\mathrm{ICH}$ process lies in the commitment for implementation by $\mathrm{ICH}$ Regulatory Members using appropriate national/regional tools ${ }^{11}$.

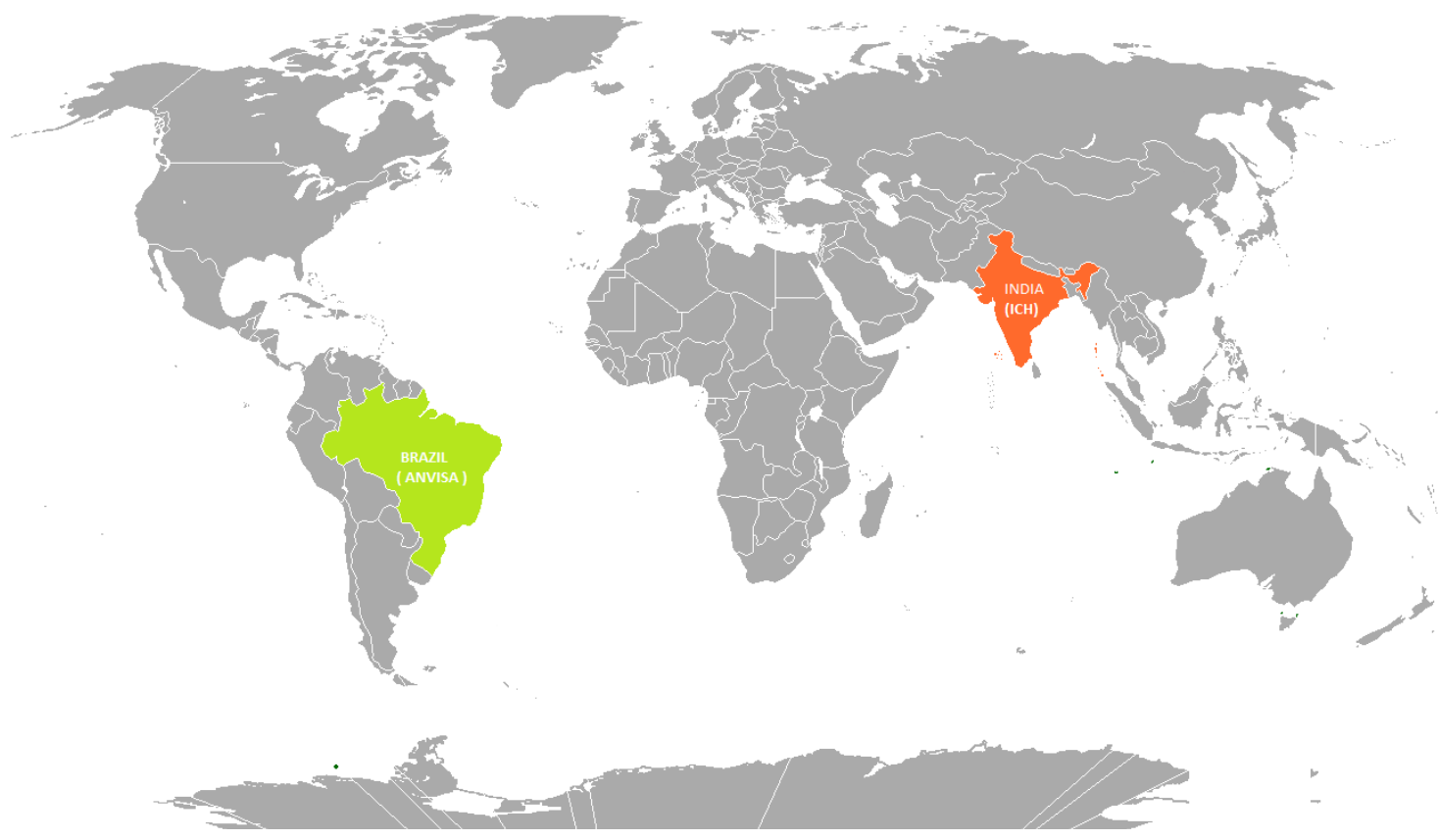

\section{Brazilian agency: ANVISA}

Brazil is the largest country in South America with a population of over 200 million people . As a growing market, Brazil has become the second largest pharmaceutical market in the emerging world, with an expectation of economic growth between 7 to $10 \%$ annually until 2020. Global pharmaceutical companies are also highly interested in investing in this vast and growing market. However, this opportunity may present a significant challenge when navigating through the complex Brazilian regulatory method.

The Brazilian Health Surveillance Agency, usually called ANVISA, abbreviated from Portuguese "Agencia Nacional de Vigilancia Sanitaria," is the food and drug regulatory agency in Brazil. ANVISA was invented in 1999 which is linked to the Ministry of Health. It is characterized by its administrative independence, financial autonomy, and by the stability of its directors. ANVISA's vision is to attain legitimation in society as an integral part of the Brazilian Unified Health System, via a nimble, modern, transparent, and domestic and international benchmark in health surveillance and regulation. ANVISA's mission is "to guard and promote public health and to intervene in the risks caused by the production and use of products regulated by health surveillance. This mission should be carried out in coordination with states, municipalities and the Federal District, according to the Brazilian Unified Health System principles, to improve the quality of life of the population." ANVISA was accepted as a new regulatory member of the International Council on Harmonization of Technical Requirements for Registration of Pharmaceuticals for Human Use $(\mathrm{ICH})$. As part of the aim to extend its global outreach, ICH, in November 2016, welcomed ANVISA from Brazil and the Ministry of Food and Drug Safety (MFDS) from South Korea. There are now 13 members and 22 observers.

\section{STABILITY GUIDELINE}

Stability - ICH Guidelines

The goal of a stability study is to control the quality of drug product or drug substance, which may vary with time. There are several environmental factors such as temperature, humidity and light which has to be considered during stability study. By means of a stability study appropriate storage conditions for the drug substance or the shelf-life for the drug product are established. The $\mathrm{ICH}$ has published several guidelines in order to give guidance to the applicant on stability testing. 


\begin{tabular}{|c|c|c|c|}
\hline Module & Topic & Last update & Information Contained \\
\hline Q1A & $\begin{array}{l}\text { Stability Testing of new drug } \\
\text { substances and products }\end{array}$ & 2003 & $\begin{array}{c}\text { This Document provides guidance on stability testing } \\
\text { for new drug substances and drug products considering } \\
\text { relevant temperature and humidity values of different } \\
\text { climatic zones. }\end{array}$ \\
\hline Q1B & $\begin{array}{c}\text { Stability Testing: } \\
\text { Photostability Testing of new drug } \\
\text { substances and products. }\end{array}$ & 1996 & $\begin{array}{l}\text { As annex to the main stability guideline (ICH Q1A),this } \\
\text { document gives guidance on how to evaluate the light } \\
\text { sensitivity of new drug substances and products. }\end{array}$ \\
\hline Q1C & $\begin{array}{l}\text { Stability Testing for new Dosage } \\
\text { forms }\end{array}$ & 1996 & $\begin{array}{l}\text { This Document provides stability guidance for new } \\
\text { formulation of already approved medicines and } \\
\text { definition of circumstances under which reduced } \\
\text { stability data can be accepted. }\end{array}$ \\
\hline Q1D & $\begin{array}{l}\text { Bracketing and Matrixing Designs } \\
\text { for Stability Testing of new drug } \\
\text { substances and products }\end{array}$ & 2002 & $\begin{array}{c}\text { General principles for reduced for stability testing (e.g. } \\
\text { bracketing matrixing designs) }\end{array}$ \\
\hline Q1E & Evaluation of stability data & 2003 & $\begin{array}{l}\text { This guidance provides possible situations where } \\
\text { extrapolated of retest period/shelf -lives beyond the } \\
\text { real time data may be appropriate (e.g. Statistical } \\
\text { appropriate to stability data analysis) }\end{array}$ \\
\hline Q1F & $\begin{array}{l}\text { Stability Data Packaging for } \\
\text { Registration Application in Climatic } \\
\text { Zones III and IV }\end{array}$ & $\begin{array}{c}2006 \\
\text { (Withdrawn) }\end{array}$ & $\begin{array}{c}\text { The ICH Steering Committee endorsed the Withdrawal } \\
\text { of the Q1F guideline decided to leave definition of } \\
\text { storage condition in Climatic Zones III and IV to the } \\
\text { respective Region s and WHO }\end{array}$ \\
\hline
\end{tabular}

\section{Stability Studies - Active Pharmaceutical Ingredient}

The stability study requirements for the Active Pharmaceutical Ingredient (API) differ depending on the country of API manufacture. In accordance with ANVISA guidance no. 02 from 2013, if the API is manufactured in Brazil or manufactured in other climate zones and used for the manufacture of drug products within Brazil for dedicated for the Brazilian market. API does not need to be tested according to ANVISA requirements ${ }^{12}$.

\section{Stability Studies - Drug Product}

Brazil established different regulations with regard to the conduction of drug product related stability studies. These cover different study aspects:

$\checkmark$ RE 01/2005 on medicinal products ${ }^{13}$

$\checkmark$ RDC 45/2012 on active pharmaceutical ingredients $^{14}$

$\checkmark$ RDC 08/2001 on some specific medicines $^{15}$

$\checkmark$ Legislative Ruling IN 04/2007 on homeopathic medicines ${ }^{16}$

There are more mandatory tests then required by the ICH guidelines. The necessity of these tests is justified by ANVISA due to Brazil's location in climatic zone IVB $^{13,17}$

In addition, the current valid Brazilian regulations require follow-up stability tests of drug product every 12 months; those studies must be performed in Brazilian territory, even for imported products (in bulk or primary packaging).

It is important to mention that Brazil initially adopted the $\mathrm{ICH}$ guideline Q1F with regard to the climatic zone classification. However, due to the lack of support from Zone IV countries claiming higher humidity than the recommended $65 \%$, Brazil implemented the WHO (World Health Organization) climatic zone IVB category (hot/very humid; $30^{\circ} \mathrm{C} / 75 \%$ $\mathrm{RH}$ ) (refer to Annex 2 for an overview of the climatic zones) $^{18,19}$

These are the general requirements for longterm and accelerated stability studies in Brazil $^{13}$

1. Climatic Zone IVB (WHO) hot and humid $\left(30^{\circ} \mathrm{C} \pm 2^{\circ} \mathrm{C} / 75 \% \mathrm{RH}\right.$ or $40^{\circ} \mathrm{C} \pm$ $\left.2^{\circ} \mathrm{C} / 75 \% \mathrm{RH}\right)$

2. Minimum data for submission 3 batches covering a minimum storage period of 12 months for long-term stability studies or 6 months for accelerated and ongoing / long-term stability studies

3. Shelf-life For a New Drug Application (NDA), the maximum provisional shelflife is 24 months. Accelerated stability data or 12-months long-term stability data, which confirm the stabilityindicating quality parameters of a drug product to change equal to or less than $5.0 \%$ in comparison to the batch release analysis results are accepted for granting the initial, provisory shelflife.

Frequency of the tests $0,3,6,9,12,18,24$ months in case of long-term stability studies and $0,3,6$ months for accelerated stability studies

Mandatory tests, unless a technical justification is presented 
$\checkmark$ appearance

$\checkmark$ quantification of active ingredient

$\checkmark$ microbiological limits

$\checkmark$ quantification of degradation products

$\checkmark \quad$ In addition for solids

\section{Dissolution (solids)}

Hardness (solids)

$>$ In addition for semi-solids or liquids

1. Sedimentation rate after agitation (for suspensions)
2. Clarity of solutions

3. Phase separation (for emulsions and creams)

4. Loss of weight (for water-based products)

Storage conditions for accelerated and long-term stability studies

$>$ The following table 3 and table 4 gives an overview of the storage conditions ${ }^{13}$

Table 3: Accelerated Stability - Drug Product

\begin{tabular}{|l|l|l|l|}
\hline Conditions & Package & $\begin{array}{l}\text { Temperature and } \\
\text { Humidity }\end{array}$ & $\begin{array}{l}\text { Storage } \\
\text { Condition }\end{array}$ \\
\hline Room & Semi-permeable & $\begin{array}{l}40^{\circ} \mathrm{C} \pm 22^{\circ} \mathrm{C} / 75 \% \\
\text { UR } \pm 5 \% \mathrm{UR}\end{array}$ & $15^{\circ} \mathrm{C}-30^{\circ} \mathrm{C}$ \\
\hline Room & Impermeable & $40^{\circ} \mathrm{C} \pm 22^{\circ} \mathrm{C}$ & $15^{\circ} \mathrm{C}-30^{\circ} \mathrm{C}$ \\
\hline Frozen & All & $-20^{\circ} \mathrm{C} \pm 5^{\circ} \mathrm{C}$ & $-20^{\circ} \mathrm{C}$ \\
\hline
\end{tabular}

Table 4: Long-Term Stability - Drug Product

\begin{tabular}{|l|l|l|l|}
\hline Conditions & Package & $\begin{array}{l}\text { Temperature and } \\
\text { Humidity }\end{array}$ & $\begin{array}{l}\text { Storage } \\
\text { Condition }\end{array}$ \\
\hline Room & Semi-permeable & $\begin{array}{l}30^{\circ} \mathrm{C} \pm 2^{\circ} \mathrm{C} / 75 \% \\
\text { UR } \pm \\
5 \%\end{array}$ & $15^{\circ} \mathrm{C}-30^{\circ} \mathrm{C}$ \\
\hline Room & Impermeable & $30^{\circ} \mathrm{C} \pm 2^{\circ} \mathrm{C}$ & $15^{\circ} \mathrm{C}-30^{\circ} \mathrm{C}$ \\
\hline Frozen & All & $-20^{\circ} \mathrm{C} \pm 5^{\circ} \mathrm{C}$ & $-20^{\circ} \mathrm{C}$ \\
\hline Refrigerated & All & $5^{\circ} \mathrm{C} \pm 3^{\circ} \mathrm{C}$ & $2{ }^{\circ} \mathrm{C}-8^{\circ} \mathrm{C}$ \\
\hline
\end{tabular}




\section{Follow up Stability Studies}

A follow-up stability study is mandatory for the drug product and requested every 12 months, including all tests of a long-term stability study. The number of selected batches depends on how many batches are produced per year (e.g.: one batch of follow-up stability for production above 15 batches/year) ${ }^{13}$.

\section{Photostability Studies}

Assessment of Brazilian Requirements In 2005, ANVISA published a guideline for photostability studies together with the resolution RE 01/2005, which Compare with the ICH Q1B.A photostability study intended for the initial marketing authorisation application of a drug product in Brazil is mandatory to be performed with three batches for the drug product $^{20}$ In addition to the guideline on photostability studies, the Brazilian resolution RDC 53/2015 established requirements for the control of degradation products and the performance ofspecific studies with regard to degradation products, which are not in line with the $\mathrm{ICH}$ guidelines .

\section{Assessment of implementation regarding ICH Q1 - Stability Studies}

The ICH Q1 guideline provides guidance on the core stability data, which are required for new drug substances and products. The currently valid Brazilian requirements for stability studies contain rigid requirements, which are not in accordance with the $\mathrm{ICH}$ guidelines.

It is important to know that the Brazilian regulatory system is based on Resolutions, which are mandatory to be followed. Even though there are additional guidelines in place, they are only in place for explanatory / recommendatory purposes, but they have to be aligned with the relevant Resolutions in force (stability and photostability).

According to the current Brazilian resolution for stability studies of new medicinal products, all stability protocols and reports, regardless of the pharmaceutical form, must contain the following information ${ }^{13}$

$\checkmark$ Description of the drug product and specification of the primary package

$\checkmark$ Batch number of each batch involved in the study

$\checkmark$ Manufacturer's description of the drug product, active ingredients

$\checkmark$ Appearance

$\checkmark$ Study plan: material, methods (design) and schedule.

$\checkmark$ Start date of the study

$\checkmark$ Amount of active ingredient and corresponding analytical method $\checkmark$ Quantification of degradation products and corresponding analytical method

$\checkmark$ Microbiological limits

$\checkmark$ Dissolution (solid form)

$\checkmark$ Hardness (solid form)

$\checkmark \mathrm{pH}$ (liquid and semisolid forms)

$\checkmark$ Sedimentation rate after agitation in suspensions (liquid and semisolid forms)

$\checkmark$ Clarity of solutions (liquid and semisolid forms)

$\checkmark$ Phase separation in emulsions and creams (liquid and semisolid forms)

$\checkmark$ Loss of weight in water-based products (liquid and semisolid forms)

\section{Stress Testing (DS) / Photostability testing (DP) \\ ICH Requirements}

The identification of degradation products under the stress conditions supports the development and validation of analytical procedures. The aim of these studies is to ensure that the external factors (e.g.: light exposure) does not result in unacceptable change in the product ${ }^{20,21}$.

\section{Assessment of Brazilian Requirements}

ANVISA issued a guideline on how to perform photostability studies as attachment to the current Brazilian resolution for stability studies ( $R E$ 01/2005). The guidance is aligned with the $\mathrm{ICH}$ Q1B ${ }^{20}$. However, while the $\mathrm{ICH}$ guidelines require the photostability study to be performed with at least one drug product batch, three drug product batches are required to be photostability tested by ANVISA ${ }^{13}$.

Besides of the requirements regarding photostability studies, the Brazilian Resolution RDC 53/2015 establishes requirements for the control of degradation products. The scope of this regulation was expanded beyond the $\mathrm{ICH}$ guideline, as The company must perform the degradation studies for all strengths of the medicinal product.

ANVISA accepts technical rationale when any of these conditions do not apply. For the implementation of the degradation studies, ANVISA published prioritisation list (Resolution RDC 53 Annex I and II) based on the therapeutic classes of the products ${ }^{22}$.

\section{Specification and required tests ICH Requirements}

These tests are needed to monitor and confirm that the drug substance / drug product does not experience any change in quality during storage under the defined conditions, which can potentially impact safety and/or efficacy of the drug product.

According to the guideline $\mathrm{ICH}$ Q6A on specifications for test procedures and 
acceptance criteria for new drug substances and new drug products (chemical substances), the following tests are mandatory: description, identification, assay and impurities including organic impurities, inorganic impurities (degradation products) and residual solvents. Tests other than those listed above may be needed in special situations ${ }^{21,23}$.

Assessment of Brazilian Requirements

The Brazilian regulation has more mandatory tests than established by the $\mathrm{ICH}$ guidelines..For all drug products the following test are mandatory: appearance, quantification of active ingredient, microbiological limits. In addition, for solids: dissolution and hardness tests and for semi-solids or liquids: $\mathrm{pH}$, sedimentation rate after agitation in suspensions, clarity of solutions solutions, phase separation in emulsions and creams and loss of weight in water-based products. All tests must be performed at each stability test point, except for the tests for hardness and microbiological purity, which are solely obligatory at the beginning and at the end point (= shelf-life) of the stability study ${ }^{13}$.

\section{Testing Frequency ICH Requirements}

The testing frequency for the long term stability studies should be every 3 months over the first year, every 6 months over the second year, and annually thereafter through the proposed re-test period/shelf-life. For the stability test under accelerated storage conditions, a 6 months study is recommended employing a testing frequency of three months (0, 3 and 6) $(\mathrm{ICH}, \mathrm{Q} 1 \mathrm{~A}(\mathrm{R} 2)$ guideline- Stability Testing of New Drug Substances and Products, 2003).

Assessment of Brazilian Requirements

The testing frequency for stability studies in Brazil is the same as defined in the $\mathrm{ICH}$ guidelines. The reduced designs (matrixing and/or bracketing), where the testing frequency is reduced or certain factor combinations are not tested at all, can be also applied (ANVISA, Brazilian Resolution - RE № 1 - Stability Studies on medicinal products, 2005).

\section{Storage Conditions}

\section{$\mathrm{ICH}$ Requirements}

In general, the stability studies for drug products applying long-term and accelerated storage conditions are sufficient. However, if there is any significant change in the quality of the drug product (e.g.: failure to meet the acceptance criteria), studies employing intermediate storage conditions must be conducted $^{21}$.

\begin{tabular}{|c|c|c|c|}
\hline STORAGE & STUDY & $\begin{array}{l}\text { STORAGE } \\
\text { CONDITION }\end{array}$ & $\begin{array}{c}\text { MINIMUM } \\
\text { TIME PERIOD } \\
\text { COVERED BY } \\
\text { DATE AT } \\
\text { SUBMISSION } \\
\end{array}$ \\
\hline Room & $\begin{array}{l}\text { Long - } \\
\text { term }\end{array}$ & $\begin{array}{c}25^{\circ} \mathrm{C} \pm 2^{\circ} \mathrm{C} / 60 \% \\
\mathrm{RH} \pm 5 \% \mathrm{RH} \\
\text { Or } \\
30^{\circ} \mathrm{C} \pm 2^{\circ} \mathrm{C} / 65 \% \\
\mathrm{RH} \pm 5 \% \mathrm{RH}\end{array}$ & 12 MONTHS \\
\hline Refrigerator & $\begin{array}{c}\text { Long - } \\
\text { term }\end{array}$ & $5^{\circ} \mathrm{C} \pm 3^{\circ} \mathrm{C}$ & 12 MONTHS \\
\hline Freezer & $\begin{array}{l}\text { Long - } \\
\text { term }\end{array}$ & $-20^{\circ} \mathrm{C} \pm 5^{\circ} \mathrm{C}$ & 12 MONTHS \\
\hline Room & $\begin{array}{c}\text { Interme } \\
\text { diate }^{*}\end{array}$ & $\begin{array}{c}30^{\circ} \mathrm{C} \pm 2 \mathrm{C} / 65 \% \\
\mathrm{RH} \pm 5 \% \mathrm{RH}\end{array}$ & 6 MONTHS \\
\hline Room & $\begin{array}{c}\text { Acceler } \\
\text { ated }\end{array}$ & $\begin{array}{c}40^{\circ} \mathrm{C} \pm 2^{\circ} \mathrm{C} / 75 \% \\
\mathrm{RH} \pm 5 \% \mathrm{RH}\end{array}$ & 6 MONTHS \\
\hline Refrigerator & $\begin{array}{l}\text { Acceler } \\
\text { ated }\end{array}$ & $\begin{array}{c}25^{\circ} \mathrm{C} \pm 2{ }^{\circ} \mathrm{C} / 60 \% \\
\mathrm{RH} \pm 5 \% \mathrm{RH}\end{array}$ & 6 MONTHS \\
\hline
\end{tabular}

* If $30^{\circ} \mathrm{C} \pm 2^{\circ} \mathrm{C} / 65 \% \mathrm{RH} \pm 5 \% \mathrm{RH}$ is the long term condition, there is no intermediate condition.

Assessment of Brazilian Requirements

In 2005, Brazil implemented the stability study requirements for WHO climatic Zone IVb category (hot/very humid; $30^{\circ} \mathrm{C} / 75 \% \mathrm{RH}$ ); this condition is not considered in the $\mathrm{ICH}$ guidelines. For the registration of the product, according to the specific resolution for stability studies (RE 01/2015), long-term stability study of 12 months or the report of the 6 months accelerated stability study are mandatory. However, RDC 200/2017 which regulates general requirements for the registration of new products, requests long-term and accelerated stability studies. Both regulations are in force with contradictory information. The main issue is that, after the official approval of a drug product, the Brazilian regulation requires follow-up stability studies every year. In addition, stability studies for imported products (as bulk or in primary packaging), have to be carried out on Brazilian territory ${ }^{21}$ 13,24

\section{Stability Evaluation ICH Requirements}

The results of the stability studies need to be evaluated in order to guarantee that the physical, chemical, biological and microbiological aspects do not show relevant changes over the storage period, which might impact the quality of the drug substance / drug product. Certain variability can be accepted; however, the results must be within the prespecified parameter ranges. Extrapolation of the real time data applying long term storage conditions is accepted and the applicant can request to extend the re-test period/shelf-life for the drug substance / drug product based on this data. However, in order to be accepted, this request needs to be technically justified (allowing extrapolation to 36 months based on 24 months stability data) ${ }^{25}$. 
Assessment of Brazilian Requirements

The Brazilian regulations offer limited options for alternative risk-based approaches and scientific justifications with regard to extrapolating stability data. Brazil regulations RE Nr. 1 and RDC Nr. 45 do not allow extrapolation of shelf-life beyond 24 months for Drug Product and API. This approach presents challenges to globally operating companies as they cannot harmonize product shelf life during product launch. while such shelf-life is limited to 24 months in Brazil until actual 36 months data are available. ${ }^{13}$

\section{ANALYTICAL VALIDATION}

Validation of analytical methods

Resolution number 166, dated July 24th, 2017 establishes the factor for the validation of analytical methods and alternative provisions. Similarly to other resolutions from ANVISA, the non-fulfillment of any criteria shall be technically justified and after the justification it will be subjected to analysis by ANVISA. Resolution 166 brings clarity on validation parameters for methods used for pharmaceutical ingredients, drug products, and biological products in all productionstages filling an important gap in guidance for the sponsors. The scope of this resolution does not embrace microbiological methods that are compendial or have been technically justified. The major point in this resolution is that an analytical method that is not described in the official compendium recognized by ANVISA requires an analytical validation. A full validation should embrace accuracy, repeatability precision, intermediate precision, selectivity, and limit of detection, limit of quantification, linearity, and interval. A partial validation mustinclude at least the parameters of precision, accuracy, and selectivity. A copy of the approved validation report or the petition number under which the final version of such report was filed must be provided In case of transfer of methods that have already been approved by ANVISA. A revalidation of an analytical method will only be considered when there are

- Changes in the synthesis or acquiring of Active Pharmaceutical Ingredient (API);

-Changes in product composition;

-Changes in the analytical method;

-Other changes that may considerably impact the validated method. ${ }^{26}$

\section{GENERAL PROVISIONS} ICH Requirements

Types of Analytical Procedures to be validated The discussion of the validation of analytical procedures is directed to the four most typical varieties of analytical procedures: $\checkmark$ Identification tests:

$\checkmark$ Quantitative tests for impurities' content;

$\checkmark$ Limit tests for the management of impurities;

$\checkmark$ Quantitative tests of the active moiety in samples of drug substance or drug product or alternative selected component(s) in the drug product.

Although there are several other analytical procedures, like dissolution testing for drug products or particle size determination for drug substance, these have not been addressed in the initial text on validation of analytical procedures. Validation of these additional analytical procedures are equally important to those listed herein and may be addressed in subsequent documents.

Identification tests are meant to make the identity of an analyte in a sample. Thiscan commonly be achieved by comparison of a property of the sample to that of a reference standard;

$\checkmark \quad$ Impurities for can be either a quantitative test or a limit test for the impurity in a sample. Test intends to accurately reflect the purity characteristics of the sample.

$\checkmark$ Assay procedures to measure the analyte present in a given sample. For the drug product, similar validation characteristics also apply when assaying for the active or for the other selected component(s).

The aim of the analytical procedure should be clearly understood since this will govern the validation characteristics which are needed to be evaluated. The Validation characteristics which need to be considered are listed below:
$\checkmark$ Accuracy
$\checkmark$ Precision
$\checkmark$ Repeatability
$\checkmark$ Intermediate
$\checkmark$ Precision
$\checkmark$ Specificity
$\checkmark$ Detection
$\checkmark$ Limit Quantitation
$\checkmark$ Limit Linearity
$\checkmark$ Range
$\checkmark$ Robustness

In the following circumstances furthermore revalidation may be necessary are:

$\checkmark$ Changes within the synthesis of the drug substance;

$\checkmark$ Changes within the composition of the finished product;

$\checkmark \quad$ Changes within the analytical procedure. The degree of revalidation required usually depends on the nature of the changes. Certain other changes may require validation as well. 


\begin{tabular}{|c|c|c|c|c|}
\hline $\begin{array}{l}\text { Type of analytical } \\
\text { procedure } \\
\text { characteristics }\end{array}$ & IDENTIFICATION & $\begin{array}{l}\text { TESTING F } \\
\text { IMPURITIES } \\
\\
\text { quantitat. }\end{array}$ & limit & $\begin{array}{l}\text { ASSAY } \\
\text { - dissolution } \\
\text { (measurement only) } \\
\text { - content/potency }\end{array}$ \\
\hline Accuracy & . & + & . & + \\
\hline Precision & & & & \\
\hline Repeatability & . & + & . & + \\
\hline Interm.Precision & . & $+(1)$ & . & $+(1)$ \\
\hline Specificity (2) & + & + & + & + \\
\hline Detection Limit & . & $\cdot(3)$ & + & . \\
\hline Quantitation Limit & . & + & . & . \\
\hline Linearity & . & + & . & + \\
\hline Range & . & + & . & + \\
\hline
\end{tabular}

- signifies that this characteristic is not normally evaluated

+ signifies that this characteristic is normally evaluated

(1) In cases where reproducibility (see glossary) has been performed, intermediate precision is not needed

(2) Lack of specificity of one analytical procedure could be compensated by other supporting analytical procedure(s)

(3) May be needed in some cases $^{10}$ 
Assessment of Brazilian Requirements

In the case of analytical methodology not described in pharmacopoeias or official forms, duly recognized by ANVISA, the methodology will be validated, provided that the following parameters are evaluated, as specified in Tables

$\checkmark$ Specificity and Selectivity $\checkmark$ Linearity

$\checkmark$ Interval

$\checkmark$ Precision

$\checkmark$ Detection Limit (Sensitivity)

$\checkmark$ Limit of Quantification

$\checkmark$ Accuracy

Robustness

\begin{tabular}{|c|c|c|c|c|}
\hline \multirow{2}{*}{ parameter Reviewed } & \multirow{2}{*}{ Identification } & \multicolumn{2}{|c|}{$\begin{array}{l}\text { test } \\
\text { dross }\end{array}$} & \multirow{2}{*}{$\begin{array}{l}\text { dosing } \\
\text { - dissolution (quantification) } \\
\text { - content uniformity } \\
\text { - power }\end{array}$} \\
\hline & & Quantitative & Limit test & \\
\hline Accuracy & not & yea & not & Yes \\
\hline precision Repeatability & not & yea & not & Yes \\
\hline Intermediate precision & not & Yes (1) & not & Yes (1) \\
\hline selectivity (z) & yea & yea & yea & yea \\
\hline Detection limit & not & $\operatorname{not}(3)$ & yea & not \\
\hline quantification limit & not & yea & not & $\operatorname{not}(3)$ \\
\hline linearity & not & yea & not & yea \\
\hline Interval & not & yea & not & yea \\
\hline
\end{tabular}

In the case of transfer of methodologies from headquarters to its subsidiaries in the Brazil and / or national companies to the equivalence study centers the methodology will be considered validated, provided parameters of precision, specificity and linearity. To guarantee the analytical quality of the results, all equipment used in the validation should be properly calibrated and analysts should be qualified and properly trained.

\begin{tabular}{|c|l|}
\hline Category & \multicolumn{1}{|c|}{ Test Purpose } \\
\hline I & $\begin{array}{l}\text { Quantitative tests for determining the active ingredient in } \\
\text { pharmaceuticals or raw materials }\end{array}$ \\
\hline II & $\begin{array}{l}\text { Quantitative tests or test limit for the determination of impurities and } \\
\text { degradation products in pharmaceutical and raw materials }\end{array}$ \\
\hline III & Performance tests (eg dissolution, active release) \\
\hline IV & Identification tests \\
\hline
\end{tabular}


Validation shall demonstrate that the analytical method produces reliable results and is suitable for the purpose it is designed in a documented way and by objective criteria.

The use of analytical method described in official compendia not recognized by Anvisa requires conducting an analytical validation, as parameters established, taking into consideration the technical operating conditions.

The compendial analytical methods should have demonstrated their suitability for the intended use, the operating conditions in the laboratory, by presenting a partial validation study.

The partial validation should evaluate at least the parameters of precision, accuracy and selectivity.

1. In the case of analytical methods for the quantification of impurities, partial validation shall include the quantification limit.

2. In the case of limit test, replacing the heading of parameters should be evaluated the parameters of selectivity and detection limit.

In the case of transfer method between laboratories, this will be deemed valid, provided that it is a study of partial validation premise receiver laboratory. The transfer method between laboratories with the same quality management system can be accomplished through a study of partial validation, in accordance with the assessment of reproducibility. ${ }^{27,28}$

\section{Analytical Parameters of Validation 1. Specificity ICH Requirements}

An investigation of specificity ought to be conducted throughout the validation of identification tests, the determination of impurities and also the assay. The procedures which are used to demonstrate specificity will depend on the intended objective of the analytical procedure. Demonstration that an analytical procedure is specific for a particular analyte (complete discrimination) is not always possible. In this case a combination of two or more analytical procedures is usually recommended to achieve the mandatory level of discrimination.

Identification appropriate identification testsought be able to discriminate between compounds of closely related structures which are likely to be present. The discrimination of a procedure is also confirmed by obtaining positive results (perhaps by comparison with a known reference material) from samples containing the analyte, including with negative results from samples which do not contain the analyte. Additionally, the identification test may be applied to materials structurally similar to or closely related to the analyte to confirm that a positive response is not obtained.

Assay and Impurity Test(s) - For chromatographic procedures, representative chromatograms ought to be used to demonstrate specificity and individual components should be appropriately labelled. In cases where a non-specific assay is used, alternate supporting analytical procedures should be used to demonstrate overall specificity. The approach is same for both assay and impurity tests. Impurities are available for the assay, this should include demonstration of the discrimination of the analyte in the presence of impurities and/or excipients; practically, this can be done by spiking pure substances (drug substance or drug product) with appropriate levels of impurities and/or excipients and demonstrating that the assay result is not affected by the presence of these materials. For the impurity test, the discrimination could also be established by spiking drug substance or drug product with appropriate levels of impurities and demonstrating the separation of these impurities individually and from other components in the sample matrix.

Impurities are unavailable - If impurity or degradation product standards are not available, specificity may be demonstrated by comparing the test results of samples containing impuritiesor degradation products to a second well-characterized procedure. Peak purity tests could also be useful to show that the analyte chromatographic peak is not attributable to more than one component (e.g., diode array, mass spectrometry). ${ }^{10}$

\section{Assessment of Brazilian Requirements}

Analytical method selectivity shall be shown by means of its ability of identifying or quantifying the analyte of interest undoubtedly in the presence of components that may be found in the sample, such as impurities, diluents and matrix components. For chromatographic methods, the chromatographic purity of the analyte signal shall be proven, except for biologic products. Identification methods, its ability of obtaining a positive result for the sample containing the analyte and a negative result for other substances present in the sample shall be demonstrated.

To demonstrate the selectivity of identification methods, the test shall be carried out with substances that are structurally similar to the analyte, and the acceptance criterion is a negative test result. 
For active pharmaceutical ingredients of vegetal origin and drug products containing such APIs, the method's ability to distinguish the material of interest from other similar vegetal materials, especially those found as adulterants and substituents, shall be demonstrated.

To reach the required level of selectivity, a combination of two or more analytical methods of identification may be needed.

For quantitative methods and limits test, selectivity shall be demonstrated by evidencing that the analytical response is due to the analyte only, without interference of the diluent, matrix, impurities or other degradation products. To show the lack of interference of degradation products, the sample has to be exposed to degradation conditions with a wide range of $\mathrm{pH}$, oxidation, heat and light. The following are exempted from the demonstration described above:

I - products whose adequacy to the resolution establishing parameters for notification, identification and qualification of degradation products in drug products has already been shown.

II - performance methods;

III - non-chromatographic methods. ${ }^{27,} 28$

\section{Linearity}

\section{$\mathrm{ICH}$ Requirements}

A linear relationship ought to be evaluated across the range of the analytical procedure. It may be demonstrated directly on the drug substance and separate weighing of synthetic mixtures of the drug product components, using the proposed procedure. The latter aspect can also be studied during investigation of the range. Evaluation of the linearity can be done by visual inspection of a plot of signals as a function of analyte concentration or content.

Test results should be evaluated by appropriate statistical methods if there is a linear relationship, for example, by calculation of a regression line by the method of least squares. In some cases, to obtain linearity between sample concentrations and assays, the test data may need to be subjected to a mathematical transformation prior to the regression analysis. The $y$-intercept, correlation coefficient, slope of the regression line and residual sum of squares should be submitted. Plots of the data need to be included. Additionally, an analysis of the deviation of the actual data points from the regression line may also be helpful for evaluating linearity.

Some analytical procedures, example immunoassays, do not demonstrate linearity after any transformation. In this case, the analytical response should be detailed by an appropriate function of the concentration of an analyte in a sample. For the establishment of linearity, a minimum of 5 concentrations is recommended. Other approaches should be justified $^{10}$.

\section{Assessment of Brazilian Requirements}

The calibration curve represents the relationship between the instrument response and the known concentration of the analyte. A calibration curve should be generated for each drug and analytical run, which will be used to calculate the drug concentration in the samples using the same biological matrix proposed for the study.

The calibration curve shall include analysis of the white sample (drug-free and internal standard-free biological matrix), the zero sample (biological matrix plus the internal standard) and at least 6 (six) samples containing drug and internal standard, contemplating the expected range of variation, from LOQ up to $120 \%$ of the highest concentration to be analyzed.

To determine the calibration curve, samples extracted from the appropriate matrix should be analyzed for at least 6 (six) different concentrations.

Alternative procedures should be justified, such as in obtaining a nonlinear correlation, where a greater number of standard concentrations will be required.

Results should be analyzed by appropriate statistical methods, such as the least-squares linear regression calculation. The curves obtained (experimental and the resulting from the mathematical treatment), the linear correlation coefficient, the angular coefficient and the line intercept must be presented.

Calibration curve acceptance criteria

$\checkmark$ less than or equal to $20 \%$ (twenty percent) deviation from the nominal concentration for the LOQ;

$\checkmark$ deviation less than or equal to fifteen percent $(15 \%)$ from the nominal concentration for the other concentrations of the calibration curve;

$\checkmark$ At least four out of six calibration curve concentrations must meet the above criteria, including the LOQ and the highest calibration curve concentration;

$\checkmark$ The linear correlation coefficient must be equal to or greater than $0.98^{27,28}$ 

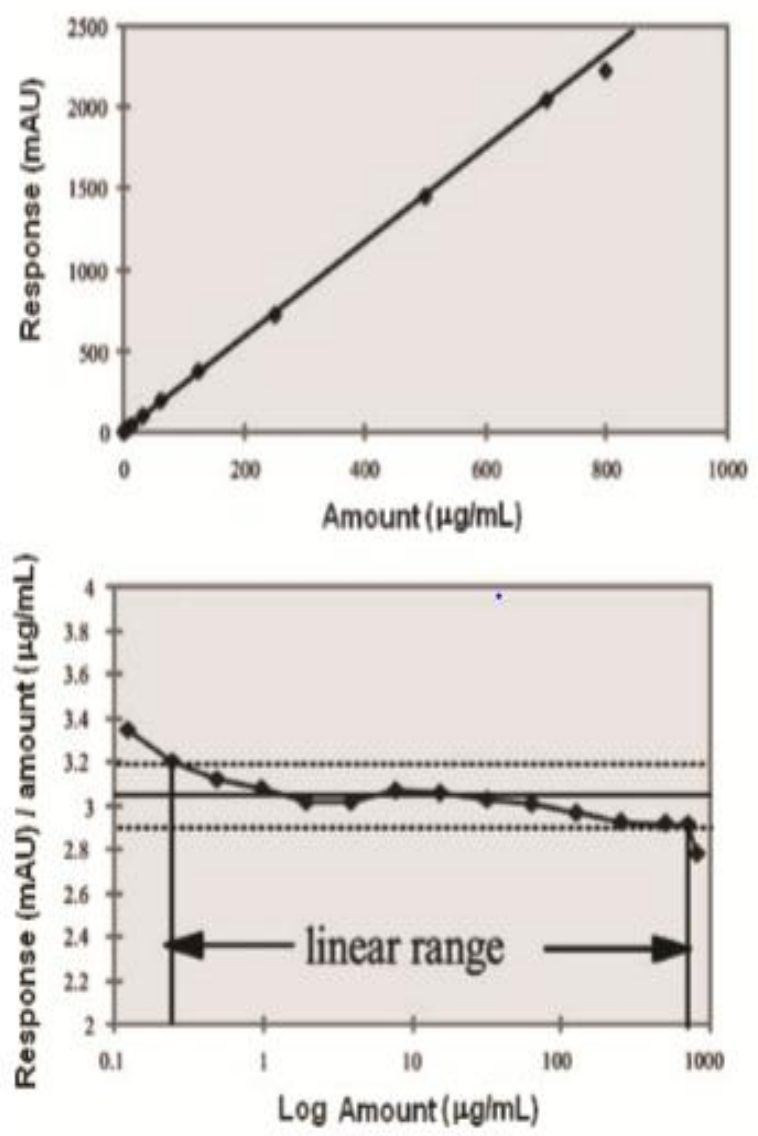

\section{Range}

\section{ICH Requirements}

The specified range is normally derived from linearity studies which depends on the intended application of the procedure. It is established by confirming that the analytical procedure provides an acceptable degree of accuracy, linearity and precision when applied to samples containing amounts of analyte within or at the limit of the specified range of the analytical procedure. The following minimum specified ranges will be considered:
1. For the assay of a drug substance normally from 80 to $120 \%$ of the test concentration;

2. For content uniformity, which covers a minimum of 70 to $130 \%$ of the test concentration, unless a wider more appropriate range, based on the nature of the dosage form (e.g., metered dose inhalers), is justified;

3. For dissolution testing the range is $+/$ $20 \%$ over the specified range

4. For the determination of an impurity: from the reporting level of an impurity from 1 to $120 \%$ of the specification;

5. For impurities known to be unusually potent or which produce toxic or an unexpected pharmacological effect, the detection/quantitation limit should be commensurate with the level at which the impurities must be controlled;

6. For validation of impurity test procedures carried out during development, it may be necessary to consider the range around a suggested limit.

7. If purity and assay are performed together as one test and only a $100 \%$ standard is used, linearity should cover the range from the reporting level of the impurities from 1 to $120 \%$ of the assay specification ${ }^{10}$.

\section{Assessment of Brazilian Requirements Interval}

The range specified is the range between the upper quantitation limits and the bottom of an analytical method. It is usually derived from the study of linearity and depends on the intended application of the method. It is established by confirmation that the method has adequate accuracy, precision and linearity when applied samples containing quantities of substances within the specified range.

Table: Percentage limits of analyte content that must be contained in the linearity range for some analytical methods ${ }^{27,28}$

\begin{tabular}{|c|c|}
\hline Test & Scope \\
\hline $\begin{array}{l}\text { Quantitative determination of analyte in } \\
\text { raw materials or pharmaceutical forms }\end{array}$ & $80 \%$ to $120 \%$ of theoretical test concentration \\
\hline Determination of impurities & $\begin{array}{l}\text { From the expected impurity level up to } 120 \% \text { of the } \\
\text { specified upper limit. Where they are of toxicological } \\
\text { significance or unexpected pharmacological effects, } \\
\text { the limits of quantitation and detection should be } \\
\text { appropriate to the amount of impurities to be } \\
\text { controlled. }\end{array}$ \\
\hline Content uniformity & $70 \%$ to $130 \%$ of theoretical test concentration \\
\hline Dissolution test & $\begin{array}{l} \pm 20 \% \text { over the specified value for the range. If the } \\
\text { specification for dissolution involves more than one } \\
\text { time, the Method range should include }-20 \% \text { over the } \\
\text { smallest value and }+20 \% \text { over the largest value. }\end{array}$ \\
\hline
\end{tabular}




\section{Accuracy}

\section{ICH Requirements}

Accuracy should be accepted across the specified range of the analytical procedurevarious methods for determining accuracy are available:

a) Implementation of the analytical procedure to synthetic mixtures of the drug product components to which known quantities of the drug substance to be analyzed have been added;

b) In cases where it is impossible to get samples of all drug product components, it may be acceptable either to add known quantities of the analyte to the drug product or to differentiate the results obtained from a second, well characterized procedure, the accuracy of which is stated and/or defined;

c) Accuracy should be concluded once precision, linearity and specificity have been established.

d) Impurities Accuracy should be assessed on drug substance/drug product spiked with known amounts of impurities. In cases where it is impossible to get samples of certain impurities and/or degradation products, it is considered acceptable to differentiate results obtained by an independent procedure. The response factor of the drug substance can also be used.

Recommended Data Accuracy should be evaluated using a minimum of 9 determinations over a minimum of 3 concentration levels covering the specified range (e.g., 3 concentrations/3 replicates each of the total analytical procedure). Accuracy should be described as percent recovery by the assay of known added amount of analyte in thesample or as the difference between the mean and the accepted true value together with the confidence intervals. ${ }^{10}$

\section{Assessment of brazilian requirements}

The accuracy of an analytical method is the proximity of the results obtained by the method under study to the true value.

Several methodologies for determining accuracy are available: a) Drug

1. Applying the proposed analytical methodology in the analysis of a substance of known purity (reference standard)

2. Comparison of the results obtained with those resulting from a well characterized second methodology, the accuracy of which has been established.

\section{b) Pharmaceutical form}

1. Analyzing a sample in which known amount of drug was added to a mixture of drug components (contaminated placebo);

2. Where samples of all drug components are unavailable, analysis by the standard addition method is accepted, in which known amounts of analyte (reference standard) are added to the drug.

\section{c) Impurities}

1. Analysis by the standard addition method, in which known amounts of impurities and / or degradation products are added to the medicament or drug

2. In the case of unavailability of samples of certain impurities and / or degradation products, comparison of the results obtained with a second well-characterized method (pharmacopoeial methodology or

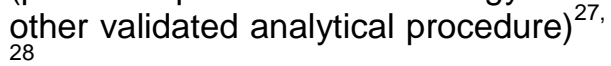

Accuracy is calculated as a percentage recovery of the known amount of analyte added to the sample, or as the percentage difference between the means and the accepted true value plus confidence intervals. The accuracy of the method must be determined after establishing the linearity, the linear range and the specificity of the method, being verified from at least 9 (nine) determinations considering the linear range of the procedure, ie 3 (three). Concentrations, low, medium and high, with 3 (three) replicates each. Accuracy is expressed by the relationship between the experimentally determined mean concentration and the corresponding theoretical concentration 
Table: Analyte recovery at different concerntration ${ }^{29}$

\begin{tabular}{lccc}
\hline Active Ingredient (\%) & Analyte ratio & Unit & Mean recovery $(\%)$ \\
\hline 100 & 1 & $100 \%$ & $98-102$ \\
$\geq 10$ & $10^{-1}$ & $10 \%$ & $98-102$ \\
$\geq 1$ & $10^{-2}$ & $1 \%$ & $97-103$ \\
$\geq 0.1$ & $10^{-3}$ & $0.1 \%$ & $95-105$ \\
$\geq 0.01$ & $10^{-4}$ & $100 \mathrm{ppm}$ & $90-107$ \\
$\geq 0.001$ & $10^{-5}$ & $10 \mathrm{ppm}$ & $80-110$ \\
$\geq 0.0001$ & $10^{-5}$ & $1 \mathrm{ppm}$ & $80-110$ \\
$\geq 0.00001$ & $10^{-7}$ & $100 \mathrm{ppb}$ & $80-110$ \\
$\geq 0.000001$ & $10^{-s}$ & $10 \mathrm{ppb}$ & $60-115$ \\
$\geq 0.0000001$ & $10^{-9}$ & $1 \mathrm{ppb}$ & $40-120$
\end{tabular}

\section{Precision}

\section{ICH Requirements}

Validation of tests for quantitative determination of impurities and for assay includes an investigation of precision.

\section{Repeatability}

Repeatability should be assessed using:

a) a minimal of 9 determinations covering the specified range for the procedure (e.g., 3 concentrations/3 replicates each);

b) a minimal of 6 determinations at $100 \%$ of the test concentration.

\section{Intermediate Precision}

The range to which intermediate precision should be proved depends on the circumstances under which the procedure is intended to be used. The applicant should prove the effects of random events on the precision of the analytical procedure. Typically, the variations which need to be studied include days, analysts, equipment, etc.

\section{Reproducibility}

Reproducibility is evaluated by means of an inter-laboratory trial. Reproducibility should be considered in the case of the standardization of an analytical procedure, for inclusion, for instance of procedures in pharmacopoeias.

\section{Recommended Data}

The standard deviation, relative standard deviation that is coefficient of variation and confidence interval should be reported for each type of precision investigated. ${ }^{10}$

\section{Assessment of Brazilian Requirements}

Precision is the evaluation of the proximity of the results obtained in a series of measurements of a multiple sampling of the same sample. This is considered on three levels.

\section{Repeatability (intra-run precision)}

Agreement between results within a short time with the same analyst and same instrumentation.

The repeatability of the method is verified by at least 9 (nine) determinations, considering the linear range of the method, that is, 3 (three) concentrations, low, medium and high, with 3 (three) replicates each or minimum of $6.100 \%$ determinations of the test concentration.

\section{Intermediate precision (inter-race precision)}

Agreement between results from the same laboratory, but obtained on different days, with different analysts and / or different equipment. For the determination of intermediate accuracy a minimum of 2 different days with different analysts is recommended.

3. Reproducibility

(inter-laboratory precision)

Agreement between results obtained in different laboratories as in collaborative studies, generally applied to standardization of analytical methodology, for example, to include methodology in pharmacopoeias. This data need not be submitted for registration grant.

The Precision of an analytical method can be expressed as the standard deviation or relative standard deviation (coefficient of variation) of a series of measurements.

Precision can be expressed as relative standard deviation (DPR) or coefficient of variation $(\mathrm{CV} \%)$ according to the formula,

$$
D P R=\frac{D P}{C M D} \times 100
$$

where SD is the standard deviation and CMD the mean concentration determined.

The maximum acceptable value should be defined according to the methodology 
employed, the concentration of the analyte in the sample, the type of matrix and the purpose of the method, with values not exceeding $5 \%{ }^{27,28}$

\section{Robustness}

\section{$\mathrm{ICH}$ Requirements}

The evaluation of robustness depends on the type of procedure under study and should be considered during the development phase. It should show the accuracy of an analysis with respect to deliberate variations in method parameters. If measurements are similar to variations in analytical conditions, the analytical conditions should be suitably controlled or a precautionary statement should be included in the procedure. One outcome of the evaluation of robustness should be that a sequence of system suitability parameters (e.g., resolution test) is established to ensure that the validity of the analytical procedure is maintained whenever used. Examples of typical variations are:

$\checkmark$ stability of analytical solutions;

$\checkmark$ extraction time.

For liquid chromatography, examples of typical variations are:

$\checkmark$ impact of variations of $\mathrm{pH}$ in a mobile phase;

$\checkmark$ influence of variations in mobile phase composition;

$\checkmark$ different columns (different lots and/or suppliers);

$\checkmark$ temperature;

$\checkmark$ flow rate.

In the case of gas-chromatography, examples of typical variations are:

$\checkmark$ different columns (different lots and/or suppliers);

$\checkmark$ temperature

$\checkmark$ flow rate. ${ }^{10}$

\section{Assessment of Brazilian Requirements}

The robustness of an analytical method is a measure of its ability to withstand small and deliberate variations of analytical parameters. Indicates your confidence during normal use.

During the development of the methodology, the robustness assessment should be considered. Given the susceptibility of the method to variations in analytical conditions, these should be controlled and precautions should be included in the procedure. ${ }^{27,28}$
Table: Factors that must be considered in determining the robustness of the analytical method

\begin{tabular}{|c|c|}
\hline Sample Preparation & $\begin{array}{c}\text { Stability of Analytical Solutions } \\
\text { Extraction Time }\end{array}$ \\
\hline Spectrophotometry & $\begin{array}{c}\text { Solution pH variation } \\
\text { Temperature } \\
\text { Different solvent manufacturers }\end{array}$ \\
\hline Liquid & Mobile phase pH variation \\
Mobile phase composition \\
variation \\
Chromatography & Different column batches or \\
& manufacturers \\
& Temperature \\
& Mobile phase flow \\
\hline Gas Chromatography & Different batches or column \\
& manufacturers \\
& Temperature \\
& Carrier gas velocity \\
\hline
\end{tabular}

\section{PHARMACEUTICAL DEVELOPMENT}

For the pharmaceutical development ANVISA follows the $\mathrm{ICH}$ Guidelines but the only difference is that, they require dissolution development report.

The harmonization of pharmaceutical development requirements and mutual recognition of pharmaceutical development inspections, is necessary to avoid duplication of work (less inspections) and also decrease of costs - for the manufacturer as well as for the authority. Also, it would speed up the process of bringing new medicines to the Brazilian market. As Brazil is an ICH member adhering to $\mathrm{ICH}$ principles, ANVISA could rely on $\mathrm{ICH}$ development of pharmaceutical product and Agencies from US/EU/JP could rely on Brazilian inspections in future. This would be a benefit for the evolving $\mathrm{ICH}$ community and would save time and money.

\section{CONCLUSION}

ANVISA was the first regulatory authority in Latin America to become a member of the $\mathrm{ICH}$. Joining the $\mathrm{ICH}$, the agency has to fulfill some obligations such as the implementation of $\mathrm{ICH}$ guidelines. The aim of this work was the critical assessment of the implementation of the $\mathrm{ICH}$ guidelines in Brazil with specific focus on the requirements for both guidelines have been selected due to the major differences between the current Brazilian resolutions and $\mathrm{ICH}$ guideline.

Based on the present assessment, many differences still exist between the current Brazilian resolutions and the $\mathrm{ICH}$ guidelines. Substantial efforts from both sides, ANVISA as well as the pharmaceutical industry, will be required in the beginning in order to implement the $\mathrm{ICH}$ guidelines in Brazil. But although many efforts and investments will be needed, it is clear that the adaption of the Brazilian dossier to the CTD format and the implementation of further $\mathrm{ICH}$ requirements 
will result in a tremendous benefit for both, the pharmaceutical industry, avoiding the need to reformat the dossier for each new drug application in Brazil, as well as for ANVISA, facilitating the regulatory reviews and communication with other health authorities.

ANVISA is putting a lot of effort in implementing the $\mathrm{ICH}$ guidelines. This includes open conversation with the pharmaceutical industry, in order to reduce the impact for both sides as much as possible and ultimately achieve the goal. ANVISA is gaining experiences on the $\mathrm{ICH}$ principles and soon they will feel more confident to completely fulfill all $\mathrm{ICH}$ requirements, and reduce the number of additional requirements for Brazil.

The harmonization of the documents will reduce duplication of studies such as different stability studies, analytical validation and pharmaceutical development which are currently performed in order to comply with different regulations of individual countries. This will speed up the access to medicinal products for the patients in Brazil.

\section{REFERENCE}

1. Teasdale, Andrew, Elder David, Nims and Raymond W. ICH Quality Guidelines: An Implementation Guide. John Wiley and Sons. 2017;1.

2. ICH Makes Organizational Changes. Zachary Brennan. Regulatory Affairs Professionals Society. 2015.

3. $\mathrm{ICH}$ is now International Council for Harmonisation. a Legal Swiss Entity, James Lind Institute.

4. International Council on Harmonisation of Technical Requirements for Registration of Pharmaceuticals for Human Use (ICH). European Medicines Agency.

5. $\mathrm{ICH}$ is now International Council for Harmonisation - a Legal Swiss Entity, James Lind Institute.

6. Dib é empossadocomodiretorpresidente da Anvisa

7. Mullin Theresa. International Regulation of Drugs and Biological Products. In Gallin, John I, Ognibene, Frederick $P$, Lee Johnson and Laura (eds.). Principles and Practice of Clinical Research. Academic Press. 2017:88

8. Lourenco $\mathrm{C}$, Orphanos $\mathrm{N}$ and Parker C. The International Council for Harmonisation: Positioning of the future with its recent reform and over 25 years of harmonisation work". Pharmaceuticals Policy and Law. 2016;18(1-4): 82.
9. Mullin Theresa . International Regulation of Drugs and Biological Products. In Gallin, John I, Ognibene, Frederick $\mathrm{P}$, Lee Johnson and Laura (eds.). Principles and Practice of Clinical Research. Academic Press. 2017;92.

10. http://www.ich.org.

11. Van Boxtel, Chris J, Santoso Budiono, Edwards annd Ralph. Drug Benefits and Risks: International Textbook of Clinical Pharmacology. IOS Press. 2008;70.

12. ANVISA Guidance n02, on climatic zone for Active Pharmaceutical Ingredient, February 2013http://portal.anvisa.gov.br/docum ents/33836/352852/Orienta\%C3\%A7 $\% \mathrm{C} 3 \% \mathrm{~A} 30+\mathrm{de}+$ Servi $\% \mathrm{C} 3 \% \mathrm{~A} 7 \mathrm{o}+\mathrm{n} \% \mathrm{C}$ $2 \% \mathrm{BA}+02+\mathrm{de}+2013+-+\mathrm{GGMED} \% 2 \mathrm{C}+$ $\mathrm{de}+01+\mathrm{de}+\quad$ fevereiro+de +2013/92b4e625-d090-400e-bbc2f90ec3a93b57

13. ANVISA- Brazilian Resolution - RE № 1 - Stability Studies on medicinal products, July 2005.https://www.diariodasleis.com.br/ busca/exibelink.php?numlink=213898.

14. Brazilian Resolution - RDC № 45Stability studies on active pharmaceutical ingredients, August 2012.https://www20.anvisa.gov.br/coif aeng/pdf/rdc45.pdf.

15. IDRAC Document- Brazilian Resolution - RE № 08 - Stability studies on some specific medicines, 2001.

16. Brazilian Normative Instruction - IN № 04 - Stability Studies on homeopathic medicines, April 2007. http://www.normasbrasil.com.br/norma /instrucao-normativa-42007_76402.html.

17. Implementation $\mathrm{ICH}$ guidelines in Brazil - Presentation Anvisa. Online Webinar in March 2018http://sindusfarma.org.br/cadastr o/index.php/site/ap_noticias/noticia/19 68.

18. WHO, Stability testing of active pharmaceutical ingredients and finished pharmaceutical products, 2009.

http://apps.who.int/medicinedocs/docu ments/s19133en/s19133en.pdf.

19. ICH Explanatory Note on the Withdrawal of $\mathrm{ICH} \quad \mathrm{Q} 1 \mathrm{~F}$. http://www.ich.org/fileadmin/Public W eb_Site/ICH_Products/Guidelines/Qua lity/Q1F/Q1F_Explanatory_Note.pdf. 
20. ICH Q1B guideline- Stability Testing : Photostability Testing of New Drug Substances and Products, November. $1996 . \quad$ https://www.ich.org/ fileadmin/Public_Web_Site/ICH_Produ cts/Guidelines/Quality/Q1B/Step4/Q1B Guideline.pdf.

21. ICH Q1A(R2) Guideline- Stability Testing of New Drug Substances and Products, February 2003.https://www.ich.org/fileadmin/Pu blic_Web_Site/ICH_Products/Guidelin es/Quality/Q1A_R2/Step4/Q1A_R2_ Guideline.pdf.

22. ANVISA. Brazilian Resolution - RDC № 25- Provisions on the procedure of documentation submission to ANVISA, June 2011. http://bvsms.saude.gov.br/bvs/saudele gis/anvisa/2011/res0025_16_06_2011 .html.

23. $\mathrm{ICH}$

Guidelines http://www.ich.org/products/guidelines. html.

24. Brazilian Resolution - RDC № 200Registration and Renewals of medicinal products in Brazil, December 2017. http://portal.anvisa.gov.

br/documents/

10181/3836387/RDC_200_2017_CO

MP.pdf/3b8c3b31-24cb-4951-a2d8-

8e6e2a48702f

25. ICH Q1E guideline - Evaluation of Stability Data, February 2003. https://www.ich.org/fileadmin/Public Web_Site/ICH_Products/Guidelines/Q uality/Q1E/Step4/Q1E_Guideline.pdf.

26. Huynh-Ba $K$ and Beumer Sassi $A$. ANVISA. An Introduction to a New Regulatory Agency with Many Challenges. AAPS Open. 2018;4.

27. http://portal.anvisa.gov.br/english

28. https://www20.anvisa.gov.br/coifaeng/l s.html

29. Analytical Method Validation Pedro Lopez Garcia1, Ernesto Buffoni1, Fabio Pereira Gomes1 and Jose Luis Vilchez Quero2 1Instituto de AperfeiçoamentoFarmacêutico (IAF) 2Department of Analytical Chemistry, Faculty of Sciences, University of Granada 1Brazil 2Spain. 